\title{
Morphological and Structural Variations in Anodic Films grown on Polished and Electropolished Titanium Substrates
}

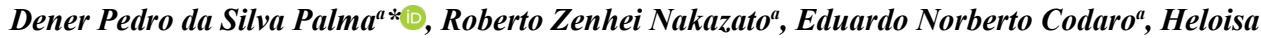 \\ Andréa Acciari ${ }^{a}$ \\ ${ }^{a}$ Departamento de Física e Química, Faculdade de Engenharia, Universidade Estadual Paulista Julio \\ de Mesquita Filho - UNESP, Guaratinguetá, SP, Brasil
}

Received: May 30, 2019; Revised: August 20, 2019; Accepted: October 10, 2019

\begin{abstract}
The objective of this work was to investigate the effects of anodization parameters on the anatase phase formation of titanium oxide films, which have been grown on both electropolished and nonelectropolished titanium surfaces by direct current anodization in 0.25 and $2.5 \mathrm{~mol} \mathrm{~L}^{-1} \mathrm{H}_{3} \mathrm{PO}_{4}$ solutions, respectively, at three anodization times (3, 6 and 12 hours). SEM, Raman spectroscopy and X-ray diffraction techniques revealed the characteristics of anodic films. Films were characterized according to presence of crystalline nuclei of anatase phase on an amorphous matrix. It was found that differences in size, shape and distribution of crystalline grains on anodized surfaces are affected by the type of polishing given to substrates. The particles on electropolished surfaces were grown in well-defined layers following cone-shaped grains. On the other hand, the crystallization phenomenon on nonelectropolished substrates has led to the appearance of smaller particle sizes and a larger number of particles distributed along the surface as well.
\end{abstract}

Keywords: titanium, electropolishing, anodization, anatase.

\section{Introduction}

In the last few decades, titanium and its alloys have been widely used in several areas of materials science, and even in biomedicine due to their desirable properties, such as biocompatibility, low density, good corrosion resistance, high mechanical strength, good formability, and also on account of not exhibiting ductile-brittle behavior when subjected to low temperatures ${ }^{1-3}$.

Some of these properties are due to native titanium dioxide film formation after being exposed to a medium containing oxygen. In biomedical applications, a positive result can be achieved when the osseointegration process is very fast and effective. However, as titanium is an inert metal when implanted in the human body, it does not effectively contribute towards making its surface more bioactive ${ }^{4}$, once native oxide films are amorphous.

Therefore, surface modification techniques such as anodization, electrodeposition, and heat treatments have generally been applied in order to increase the crystallinity of oxide films and improve their surface properties ${ }^{5}$. Anodization is an important electrochemical surface modification technique, which consists in growing an oxide film with high adhesion to the substrate which is able to promote an increase in thickness and crystallinity of the passive film ${ }^{2,6,7}$.

In recent years, new methodologies for the anodization process have been developed in order to promote the growth of $\mathrm{TiO}_{2}$ films at relatively low temperatures and potentials. These researches aim to change anodization parameters so as

*e-mail: dener.palma@unesp.br. to form films with different characteristics, e.g. thin or thick, compact or porous, micro or nanostructured, and amorphous or crystalline ${ }^{8-10}$. Several studies have been conducted with the aim of better understanding their formation and growth mechanism. Among which, some have found that the anatase phase shows better interaction with osteoblasts than amorphous or rutile phases. In addition, porous films are important on account of favoring anchorage of osteoblasts and improve the osseointegration process ${ }^{11-12}$.

Electrolytes used in titanium anodization can be either acidic or basic, and the most commonly ones used are: $\mathrm{NH}_{4} \mathrm{~F}$, $\mathrm{H}_{2} \mathrm{SO}_{4}, \mathrm{H}_{3} \mathrm{PO}_{4}, \mathrm{HNO}_{3}, \mathrm{CH}_{3} \mathrm{COOH}$, and their mixtures. When anodization is carried out in solutions containing fluoride ions, $\mathrm{TiO}_{2}$ nanotubes are generally formed ${ }^{13}$, which have an organized porous structure. On the other hand, $\mathrm{H}_{3} \mathrm{PO}_{4}$ offers some advantages when compared to other electrolytes, such as growth of titanium dioxide porous films. Moreover, phosphate ions present in titanium dioxide films increase the biocompatibility of implants due to calcium phosphate formation from the interaction of phosphate ions with the bone tissue ${ }^{11,14,20}$.

The effect of anodization time and applied potential on the characteristics of anodic films has been studied by several authors, who have found that a small variation in these parameters can significantly modify surface morphology, roughness, porosity and crystallinity of films. Thus, the longer the anodization time, the higher the percentage of rutile and anatase phases becomes, i.e. a higher crystallinity of films is achieved ${ }^{14-16}$. Thereby, this work aimed to investigate the relation between anodization parameters and film characteristics. 
The effects of surface finishing, electrolyte concentration and anodization time on the morphology and structure of titanium oxide films have also been discussed herein.

\section{Materials and Methods}

Commercially pure titanium with a hexagonal close packed crystal structure at room temperature is classified into four different grades, according to the impurities content present in its crystalline structure ${ }^{17}$. Commercially pure titanium grade 2 samples with an area of $1 \mathrm{~cm}^{2}$ and $2 \mathrm{~mm}$ of thickness has been selected for this work. Samples were mechanically ground with $\mathrm{SiC}$ paper whose grit sizes range from 180 to 1200 (mesh), which were then separated into a couple of sets of final polishing: electropolishing (EP) and mechanical polishing (MP). EP was carried out on a Buehler Electromet 4 machine using a bath of $940 \mathrm{~mL}$ of acetic acid and $60 \mathrm{~mL}$ of perchloric acid. The tests were carried out at room temperature with an applied potential of $45 \mathrm{~V}$ during $90 \mathrm{~s}$ for each sample, which were then positioned on a PVC mask with a central stainless steel device over the cathode. The experimental conditions adopted in this section establish optimal parameters of electropolishing evaluated for titanium in accordance with the electrolyte used herein in order to obtain a mirror finish. MP was conducted at low rotational speed and finished with $\mathrm{Al}_{2} \mathrm{O}_{3}$ particles in suspension with $1 \mu \mathrm{m}$ in size. Thereafter, all samples were ultra-sonically cleaned in deionized water and then air-dried. The films were obtained by anodization in 0.25 and $2.5 \mathrm{~mol} \mathrm{~L}^{-1} \mathrm{H}_{3} \mathrm{PO}_{4}$ solutions at three anodization times (3, 6 and 12 hours) by applying a potential of $30 \mathrm{~V}$ in potentiostatic mode. Its setup consisted of a copper plate as cathode and each titanium sample as anode (Figure 1). Thus, four groups of samples have been investigated: i) electropolished samples (EP) anodized in a $2.5 \mathrm{~mol} \mathrm{~L}^{-1} \mathrm{H}_{3} \mathrm{PO}_{4}$ solution; ii) electropolished samples (EP) anodized in a $0.25 \mathrm{~mol} \mathrm{~L}^{-1} \mathrm{H}_{3} \mathrm{PO}_{4}$ solution; iii) mechanically polished samples (MP) anodized in a $2.5 \mathrm{~mol}$ $\mathrm{L}^{-1} \mathrm{H}_{3} \mathrm{PO}_{4}$ solution; iv) mechanically polished samples (MP) anodized in a $0.25 \mathrm{~mol} \mathrm{~L}^{-1} \mathrm{H}_{3} \mathrm{PO}_{4}$ solution. For all groups, anodization time varied in each case.

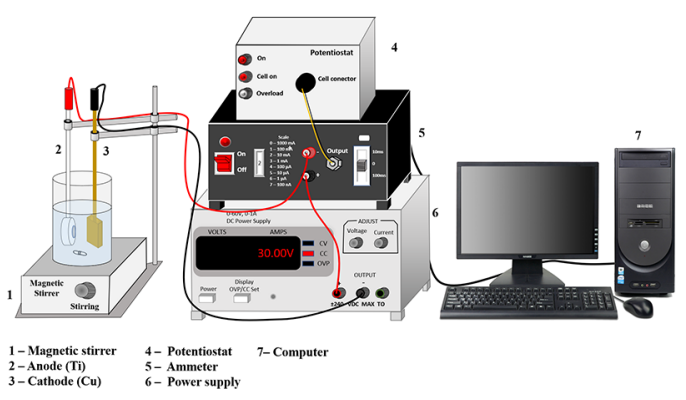

Figure 1. Schematic drawing of the anodization system coupled to a potentiostat. An electrochemical interface connected via computer was used to record current data as a function of time.
Titanium oxide films were identified using a Horiba Scientific T64000 Raman spectrometer through laser radiation beam with excitation wavelength of $514 \mathrm{~nm}$ (10-fold $60 \mathrm{sec}$ exposure to obtain each spectrum). Surface topography was analyzed by scanning electron microscopy (SEM, ZEISS DSM 940). Phase analysis was evaluated by using a Bruker D8 Advance Phaser diffractometer with $\mathrm{CuK} \alpha$ radiation. Data were acquired through low-angle X-ray diffraction at $2 \theta$ values of $20^{\circ}$ to $60^{\circ}$ and a scanning rate of $0.5^{\circ} \mathrm{min}^{-1}$.

\section{Results and Discussion}

Figure 2 shows the anodization graphs displaying current density values as a function of time for both types of polishing methods at three different anodization times and two concentrations of a $\mathrm{H}_{3} \mathrm{PO}_{4}$ solution. By analyzing the curves obtained during anodization, it is observed that the current increases gradually at the beginning of anodization until it reaches peak value, i.e. between 3 and $10 \mathrm{~mA} \mathrm{~cm}^{-2}$, and then current density decreases to a value which is close to zero.

According to literature, anodization curves can be divided into three stages, as shown in Figure 2 (a). The first one (I) is represented by an initial drop in current density, which is caused by an instantaneous formation of a thin oxide film on the titanium substrate. Then, in stage II, there is an increase in current which is due to the anodic film growth by a reaction between titanium (IV) and hydroxide ions to form titanium dioxide. In the last stage (III), current density decreases, which indicates that the film has reached maximum thickness ${ }^{18,19}$.

The areas under the graph curves in Figure 2 represent the thicknesses of films, which have been calculated according to Faraday's Law, as shown in Table 1. It was observed that surface finishing and electrolyte concentration significantly affect anodic film growth. In both types of surfaces, film thickness increases as anodization time elapses, with the exception of that calculated for the MP sample in a $0.25 \mathrm{~mol} / \mathrm{L}$ solution after $6 \mathrm{~h}$, which is smaller than that obtained after $3 \mathrm{~h}$ of anodization time. In fact, differences in thicknesses are more pronounced on electropolished surfaces (EP), in addition to being more significantly affected by electrolyte concentration. This result may be associated with differences in the number of crystalline nuclei on electropolished surfaces, which is larger for samples after anodization using a more diluted electrolyte. Furthermore, the differences are negligible when comparing thicknesses according to anodization times for mechanically polished substrates (MP). This fact may be associated with surface roughness, in addition to the presence of microdefects resulting from mechanical polishing, which act as preferential sites of nucleation and growth for anodic films. As a result, film growth rate is higher on the mechanically polished surface (MP) if compared to the electropolished substrate (EP). 
(a)

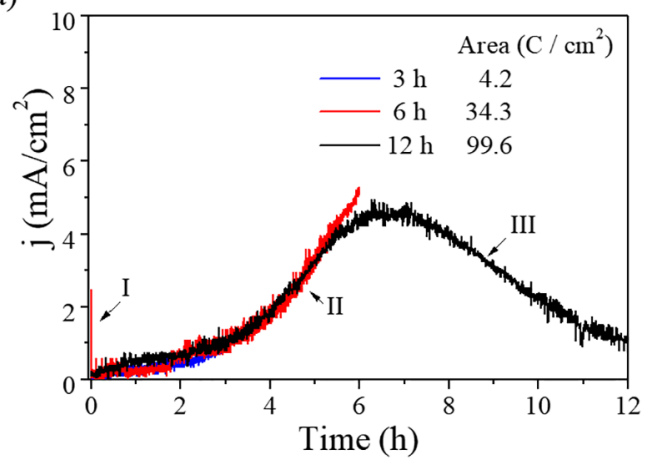

(c)

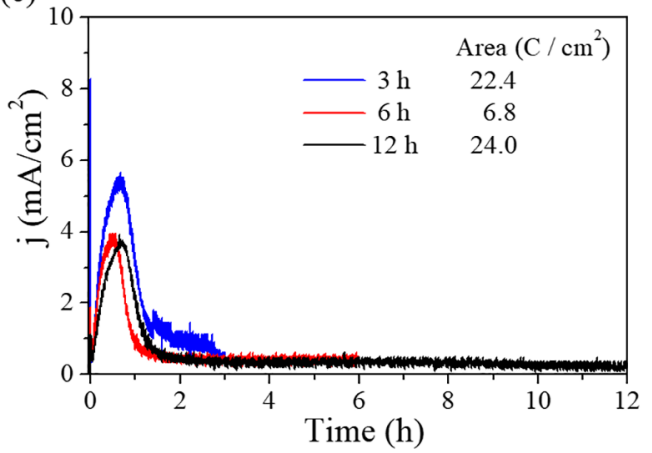

(b)

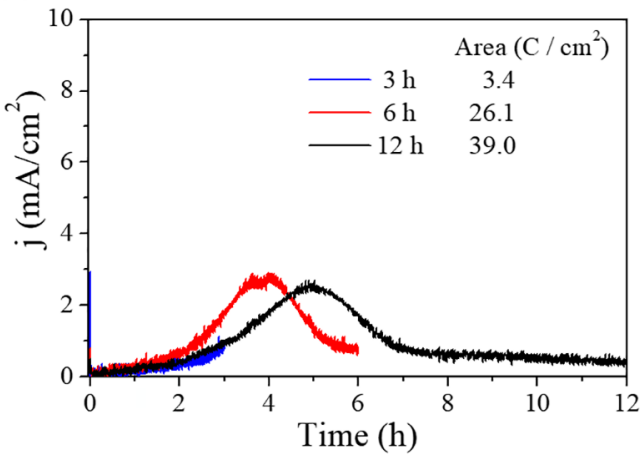

(d)

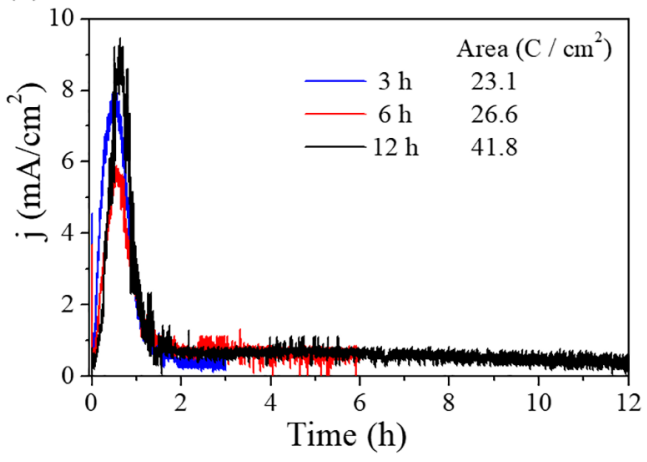

Figure 2. Anodization graphs for electropolished $(\mathrm{a}, \mathrm{b})$ and mechanically polished $(\mathrm{c}, \mathrm{d})$ titanium substrates in $0.25(\mathrm{a}, \mathrm{c})$ and $2.5 \mathrm{~mol} \mathrm{~L}^{-1}$ (b,d) $\mathrm{H}_{3} \mathrm{PO}_{4}$ solutions.

Table 1. Thickness estimation of anodic film samples calculated according to Faraday's law.

\begin{tabular}{|c|c|c|c|c|}
\hline \multirow{3}{*}{$\begin{array}{l}\text { Anodization } \\
\text { time (h) }\end{array}$} & \multicolumn{4}{|c|}{ Thickness of film $(\mu \mathrm{m})$} \\
\hline & \multicolumn{2}{|c|}{ Electropolished samples (EP) } & \multicolumn{2}{|c|}{ Mechanically polished samples (MP) } \\
\hline & $0.25 \mathrm{~mol} \mathrm{~L}^{-1}$ & $2.5 \mathrm{~mol} \mathrm{~L}^{-1}$ & $0.25 \mathrm{~mol} \mathrm{~L}^{-1}$ & $2.5 \mathrm{~mol} \mathrm{~L}^{-1}$ \\
\hline 3 & 2.2 & 1.7 & 11.6 & 12.1 \\
\hline 6 & 17.8 & 13.6 & 8.75 & 13.8 \\
\hline 12 & 51.9 & 20.3 & 12.5 & 21.7 \\
\hline
\end{tabular}

This result is supported by SEM images obtained for both electropolished and mechanically polished titanium substrates after anodization at different anodization times and two electrolyte concentrations. According to Figures 3 and 4, there are two distinct regions, a darker area with the presence of numerous light spots that grow in number according to increased anodization time. This number appears to be much larger on electropolished titanium substrates (EP) if compared to those on mechanically polished substrates (MP). Therefore, it is assumed that the light spots in SEM images correspond to crystalline nuclei which are spread in an amorphous phase (dark area). By comparing Figures 3 and 4 , it can be seen that the effect of anodization time and electrolyte concentration are not as pronounced on MP surfaces as on EP surfaces, which may be due to the fact that film growth is faster on the MP substrate than on EP surfaces. In other words, MP samples were coated with crystalline nuclei over the entire length of the anodized surface, thus indicating that crystalline grains were uniformly distributed. For these samples, no variation in film morphology was observed with increased anodization time or from the variation of electrolyte concentration, as depicted in Figure 4. The thickness of the film grown on EP substrates increases as anodization time elapses for both electrolytes. However, the same behavior cannot be observed for films grown on MP surfaces. This result supports the hypothesis that surface finishing can affect the anodic film morphology.

A quantitative analysis of crystalline grains was carried out by means of digital image processing, which distinguishes different color shades and calculates the covered area percentage through a given color hue. As the images presented two distinct color shades, the software counted 

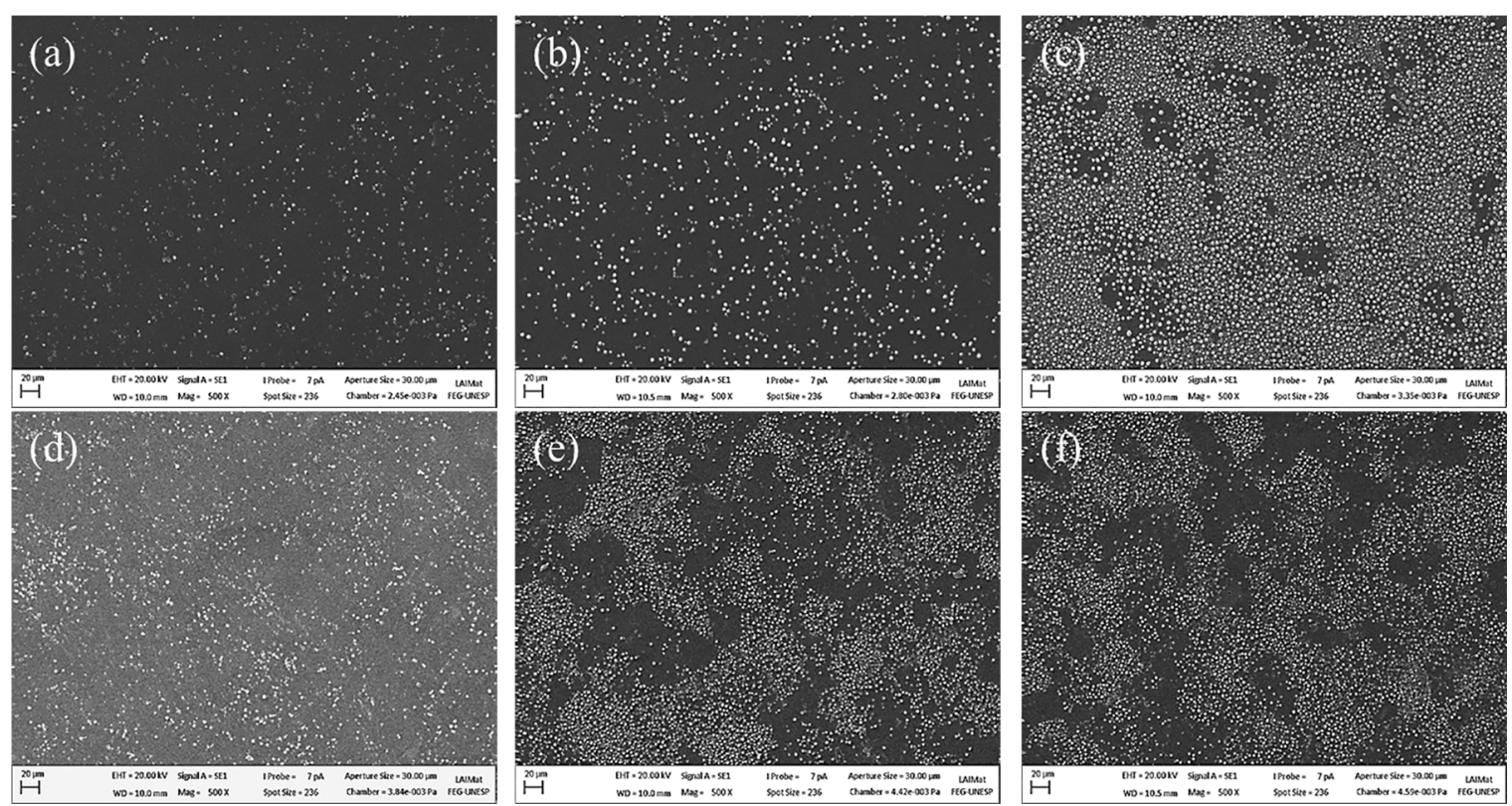

Figure 3. SEM images obtained using a secondary electron detector for electropolished titanium substrates (EP) after anodization at different anodization times: $3 \mathrm{~h}(\mathrm{a}, \mathrm{d}), 6 \mathrm{~h}(\mathrm{~b}, \mathrm{e}), 12 \mathrm{~h}(\mathrm{c}, \mathrm{f})$; and two electrolyte concentrations $\left(\mathrm{H}_{3} \mathrm{PO}_{4}\right.$ solution, in mol L $\left.\mathrm{L}^{-1}\right): 0.25$ (a-c), 2.5 (d-f).
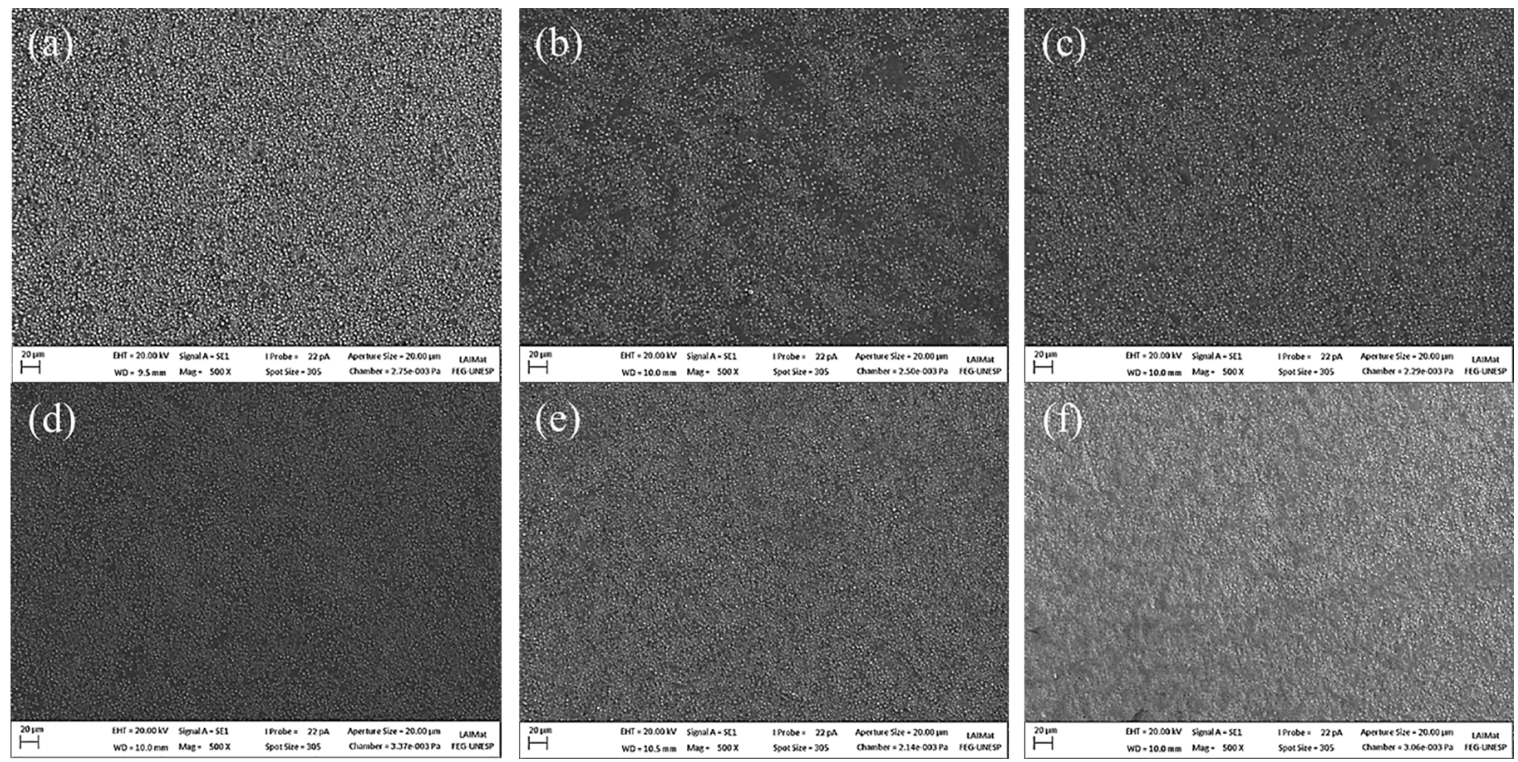

Figure 4. SEM images obtained using a secondary electron detector for mechanically polished titanium substrates (MP) after anodization at different anodization times: $3 \mathrm{~h}(\mathrm{a}, \mathrm{d}), 6 \mathrm{~h}(\mathrm{~b}, \mathrm{e}), 12 \mathrm{~h}(\mathrm{c}, \mathrm{f})$; and two electrolyte concentrations $\left(\mathrm{H}_{3} \mathrm{PO}_{4}\right.$ solution, in mol $\left.\mathrm{L}^{-1}\right): 0.25(\mathrm{a}-\mathrm{c})$, $2.5(\mathrm{~d}-\mathrm{f})$.

light spots in light gray and the amorphous area in dark gray. After applying the contrast technique, the colors shades in images were the opposite, i.e. the light gray spots in images shown by Figures 3 and 4 became black spots in processed images. In contrast, the dark gray area was converted into a white area. For EP samples, the number of crystalline spots between 6 and $12 \mathrm{~h}$ increases significantly after anodization in a $0.25 \mathrm{~mol} \mathrm{~L}^{-1} \mathrm{H}_{3} \mathrm{PO}_{4}$ solution and $78 \%$ of surface area is covered after $12 \mathrm{~h}$, as shown in Table 2 . On the other hand, after anodization in a $0.25 \mathrm{~mol} \mathrm{~L}^{-1} \mathrm{H}_{3} \mathrm{PO}_{4}$ solution, the coating rate of crystalline grains on the substrate was $52 \%$.

According to the results shown in Table 2, it was found that the kinetics of amorphous film growth and its transition to a crystalline phase are influenced by the substrate surface roughness by assuming that the light spots in SEM images correspond to crystalline grains of titanium dioxide.

Figure 5 shows surface morphologies before and after the anodization process. Before anodization, it can be observed 
Table 2. Quantitative analysis results using an image processor.

\begin{tabular}{|c|c|c|c|c|}
\hline \multirow{3}{*}{$\begin{array}{l}\text { Anodization } \\
\text { time (h) }\end{array}$} & \multicolumn{4}{|c|}{ Crystalline grains percentage (covered area percentage) } \\
\hline & \multicolumn{2}{|c|}{ Electropolished samples (EP) } & \multicolumn{2}{|c|}{ Mechanically polished samples (MP) } \\
\hline & $0.25 \mathrm{~mol} \mathrm{~L}^{-1}$ & $2.5 \mathrm{~mol} \mathrm{~L}^{-1}$ & $0.25 \mathrm{~mol} \mathrm{~L}^{-1}$ & $2.5 \mathrm{~mol} \mathrm{~L}^{-1}$ \\
\hline 3 & 4 & 15 & 78 & 81 \\
\hline 6 & 9 & 29 & 75 & 84 \\
\hline 12 & 78 & 52 & 71 & 70 \\
\hline
\end{tabular}

a smooth surface of titanium substrates with no significant contrast in topography, as shown in Figure $5(a, b)$. EP surfaces showed a wavier pattern than MP surfaces, although the two types of substrates had a mirrored finish. Figure 5 (c) shows the anodic oxide surface in higher magnification, which was grown on EP surfaces in well-defined layers following cone-shaped grains. The grains on MP substrates, shown in Figure $5(\mathrm{~d})$, are smaller than those on EP samples, which are well distributed on the surface.

Similarly, this phenomenon might be explained by the crystal growth in a precipitation process from a supersaturated solution. Precipitation consists in two distinct events: nucleation, or the initial formation of smaller stable crystals, and their subsequent growth. Smaller crystals are formed when nucleation rate exceeds crystal growth rate. A supposed mechanism might be associated with their nucleation in preferential sites located on the grain boundaries. However, they are randomly distributed on the surface and their nucleation and growth may be associated with the presence of micro-defects resulting from the polishing process. Thus, it is assumed that this structure arises from microcrystals nucleated on the titanium surface, which is probably due to high local current density. After nucleation, microcrystals grow rapidly on account of higher ionic conductivity if compared to the amorphous phase ${ }^{19}$.
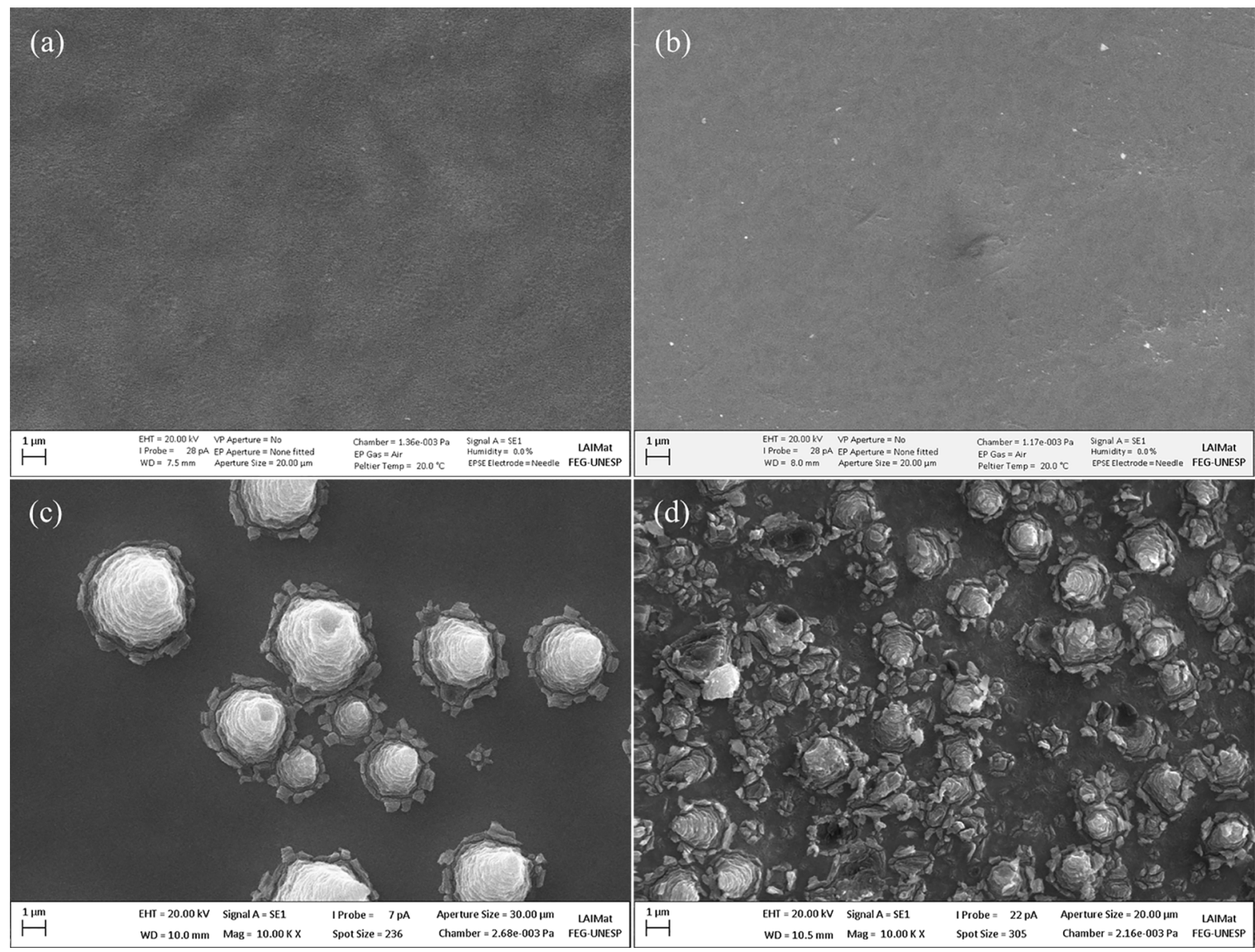

Figure 5. SEM images obtained using a secondary electron detector at higher magnification for EP (a) and MP (b) substrates before anodization. Film morphology is shown for EP (c) and MP (d) substrates after $6 \mathrm{~h}$ of anodization in a $2.5 \mathrm{~mol} \mathrm{~L}^{-1} \mathrm{H}_{3} \mathrm{PO}_{4}$ solution. 
The Raman spectra of anodic oxide films at cone-shaped grains revealed bands of around 147,397, 517 and $638 \mathrm{~cm}^{-1}$, as shown in Figure 6. A strong band of around $147 \mathrm{~cm}^{-1}$ is assigned to a long-range order of the anatase phase, whereas other bands are due to a short-range order of the anatase phase ${ }^{20,21}$. These results are in good agreement with literature data and may indicate that cone-shaped grains refer to areas of high degree of crystallization ${ }^{19,20}$. On the other hand, in the darker area of a compact layer around the cone-shaped grains (dashed lines in Figure 6), no Raman peaks were found which are generally associated with amorphous or nanocrystalline films. It has been reported that the crystallization degree of titanium anodic oxide films is a function of anodization time. Xing et al. demonstrated that there is a transition time for growth and crystallization of films, which depends on applied potential and anodization time. According to the authors, when anodization time is longer than a critical value for a given applied potential, the electric field is directed towards increasing the degree of crystallization, instead of increasing thickness ${ }^{19}$.

The film structure on anodized titanium has also been investigated by low-angle X-ray diffraction. Figure 7 shows XRD pattern of titanium oxide film grown on EP surface after $12 \mathrm{~h}$ of anodization in a $0.25 \mathrm{~mol} \mathrm{~L}^{-1} \mathrm{H}_{3} \mathrm{PO}_{4}$ solution. The curve shows that the crystalline anatase phase was detected on the surface of this sample. For the other experimental conditions, the curves only showed peaks of titanium substrate ${ }^{22}$, as shown in Figure 7 (b) for the MP substrate after anodization in the same condition, thereby not shown herein. In this respect, X-ray diffraction might not be the most suitable technique to identify the anatase phase presence on the anodized surfaces, since it might have been heterogeneously distributed along the amorphous phase, thus not forming a continuous crystalline film.
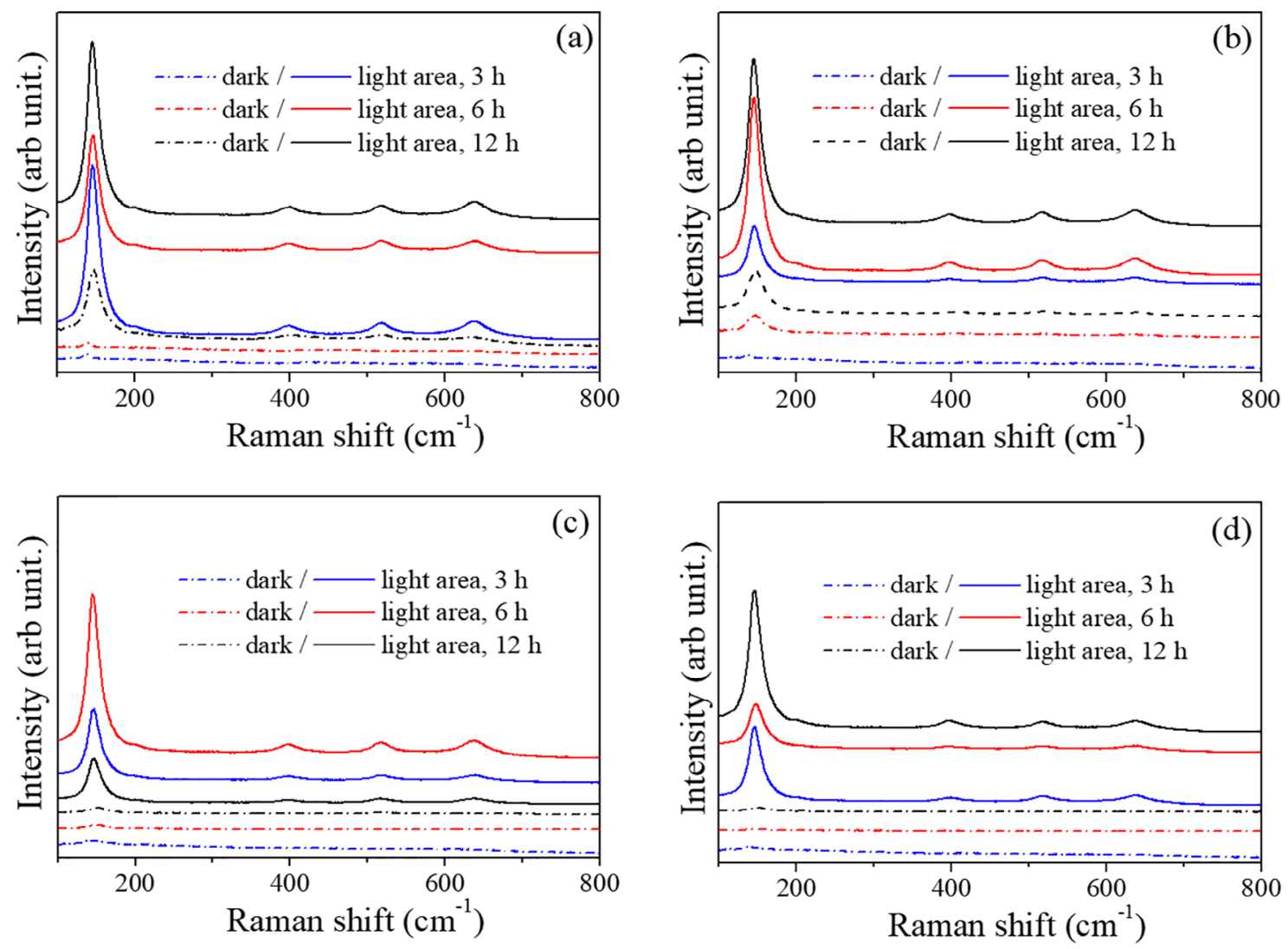

Figure 6. Raman spectra obtained for titanium oxide films after anodization in two different concentrations (mol L-1): $0.25(\mathrm{a}, \mathrm{c})$ and 2.5 (b, d) $\mathrm{H}_{3} \mathrm{PO}_{4}$ solutions; on EP (a, b) and MP (c, d) substrates. 

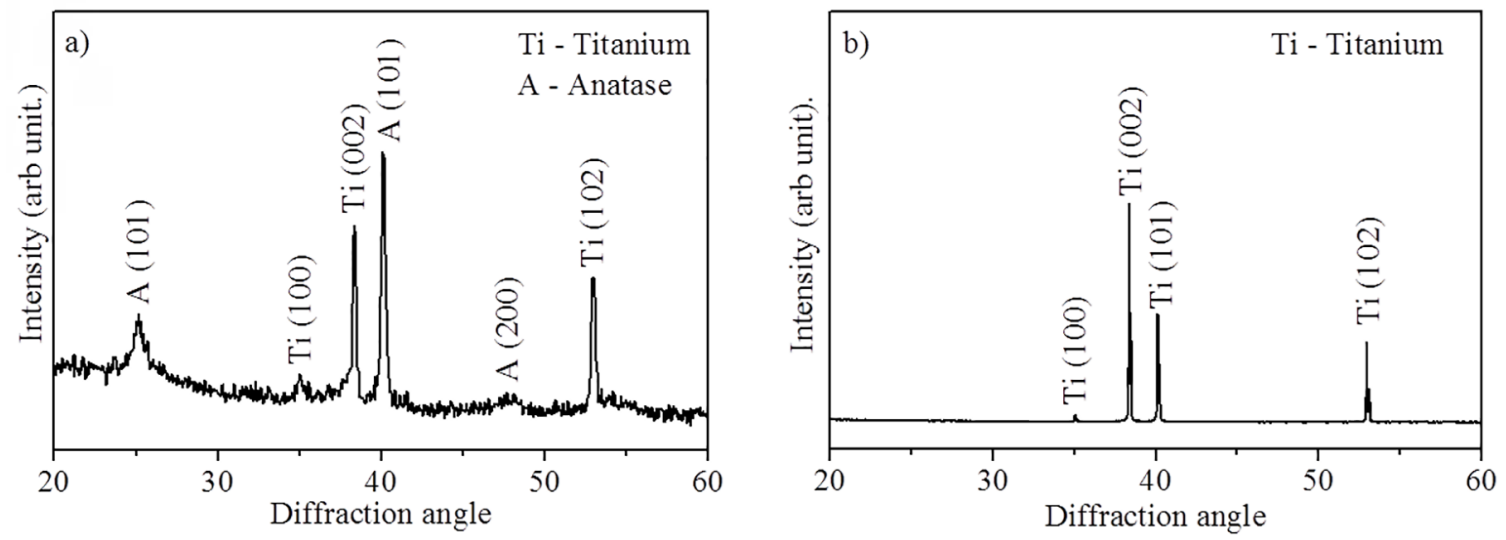

Figure 7. X-ray patterns obtained for EP (a) and MP (b) titanium surfaces after $12 \mathrm{~h}$ of anodization time in a $0.25 \mathrm{~mol} \mathrm{~L}^{-1} \mathrm{H}_{3} \mathrm{PO}_{4}$ solution.

\section{Conclusion}

This work establishes the relevance of surface pretreatment in investigating the characteristics of titanium oxide films formed by anodization in different experimental conditions. In summary, the results indicate that surface finishing significantly modify the morphology and kinetics of film growth. They presented crystalline nuclei of anatase phase in well-defined layers following cone-shaped grains on an amorphous matrix. Film thickness and percentage of crystalline grains depend on electrolyte concentration and anodization time in different ways by comparing the two types of substrates. On MP surfaces, film thickness and percentage of crystalline grains have not been significantly affected by the anodization parameters used in this study. On the other hand, on EP surfaces, they increase as anodization time increases. Thinner films have been obtained after anodization using more concentrated solution.

\section{Acknowledgments}

D.P.S.P. acknowledges the MSc. scholarship granted by CAPES, Brazil. The authors would also like to acknowledge the financial support from FAPESP and PROPe/UNESP. Furthermore, the authors are thankful to Professor Luis Rogerio de Oliveira Hein for providing the SEM images and the Multiuser Laboratory for Advanced Optical Spectroscopy (IQ-Unicamp) for the Raman spectra.

\section{References}

1. Mohammed MT. Development of a new metastable beta titanium alloy for biomedical applications. Karbala International Journal of Modern Science. 2017;3(4):224-230.

2. Kang KW, Limandri S, Castellano G, Suárez S, Trincavelli J. Thickness determination of anodic titanium oxide films by electron probe microanalysis. Materials Characterization. 2017;130:50-55.
3. Soro N, Brassart L, Chen Y, Veidt M, Attar H, Dargusch MS. Finite element analysis of porous commercially pure titanium for biomedical implant application. Materials Science and Engineering: A. 2018;725:43-50.

4. Domínguez-Trujillo C, Ternero F, Rodríguez-Ortiz JA, Heise S, Boccaccini AR, Lebrato J, et al. Bioactive coatings on porous titanium for biomedical applications. Surface and Coatings Technology. 2018;349:584-592.

5. Shah A, Ismail SNF, Hassam MA, Daud R. Surface Modification on Titanium Alloy for Biomedical Application. In: Beddows C. Reference Module in Materials Science and Materials Engineering. Amsterdam: Elsevier; 2018. p. 1-9.

6. Ohtsu N, Hirano Y, Takiguchi K. Comparison of NiTi alloy surfaces formed by anodization in nitric, phosphoric, and sulfuric acid electrolytes. Surface and Coatings Technology. 2018;335:306-313.

7. Choudhary RK, Mishra P, Kain V, Singh K, Kumar S, Chakravartty JK. Scratch behavior of aluminum anodized in oxalic acid : Effect of anodizing potential. Surface and Coatings Technology. 2015;283:135-147.

8. Si HY, Sun ZH, Kang X, Zi WW, Zhang HL. Voltage-dependent morphology, wettability and photocurrent response of anodic porous titanium dioxide films. Microporous and Mesoporous Materials. 2009;119(1-3):75-81.

9. Oliveira NCM, Moura CCG, Zanetta-Barbosa D, Mendonça DBS, Mendonça G, Dechichi P. Effects of titanium surface anodization with $\mathrm{CaP}$ incorporation on human osteoblastic response. Materials Science and Engineering: C. 2015;33(4):19581962.

10. Hatamleh MM, Wu X, Alnazzawi A, Watson J, Watts D. Surface characteristics and biocompatibility of cranioplasty titanium implants following different surface treatments. Dental Materials. 2018;34(4):676-683.

11. Simka W, Sadkowski A, Warczak M, Iwaniak A, Dercz G, Michalska J, et al. Characterization of passive films formed on titanium during anodic oxidation. Electrochimica Acta. 2011;56(24):8962-8968. 
12. Lv L, Li K, Xie Y, Cao Y, Zheng X. Enhanced osteogenic activity of anatase $\mathrm{TiO}_{2}$ film: Surface hydroxyl groups induce conformational changes in fibronectin. Materials Science and Engineering: C. 2017;78:96-104.

13. Huang X, Liu Z. Growth of titanium oxide or titanate nanostructured thin films on Ti substrates by anodic oxidation in alkali solutions. Surface and Coatings Technology. 2013;232:224-233.

14. Krasicka-Cydzik E. Anodic Layer Formation on Titanium and Its Alloys for Biomedical Applications. In: Amin AKMN, editor. Titanium Alloys - Towards Achieving Enhanced Properties for Diversified. London: IntechOpen; 2012. p. 174-200.

15. Wu L, Liu J, Yu M, Li S, Liang H, Zhu M. Effect of anodization time on morphology and electrochemical impedance of andic oxide films on titanium alloy in tartrate solution. International Journal of Electrochemical Science. 2014;9(9):5012-5024.

16. Kapusta-Kołodziej J, Syrek K, Pawlik A, Jarosz M, Tynkevych $\mathrm{O}$, Sulka GD. Effects of anodizing potential and temperature on the growth of anodic $\mathrm{TiO}_{2}$ and its photoelectrochemical properties. Applied Surface Science. 2017;396:1119-1129.

17. ASTM International - Helping our world work better. ASTM F67-13 - Standard Specification for Unalloyed Titanium, for
Surgical Implant Applications (UNS R50250, UNS R50400, UNS R50550, UNS R50700). West Conshohocken, PA: ASTM International; 2013. p. 1-6.

18. Wang N, Li H, Lü W, Li J, Wang J, Zhang Z, et al. Effects of $\mathrm{TiO}_{2}$ nanotubes with different diameters on gene expression and osseointegration of implants in minipigs. Biomaterials. 2011;32(29):6900-11.

19. Xing J, Xia Z, Hu J, Zhang Y, Zhong L. Time dependence of growth and crystallization of anodic titanium oxide films in potentiostatic mode. Corrosion Science. 2013;75:212-219.

20. Chen Z, Zhou K. Surface morphology, phase structure and property evolution of anodized titanium during water vapor exposure. Surface and Coatings Technology. 2015;263:61-65.

21. Giorgi L, Salernitano E, Makris TD, Giorgi R, Leoni E, Grilli ML, et al. Titania nanotubes self-assembled by electrochemical anodization: Semiconducting and electrochemical properties. Thin Solid Films. 2016;601:28-34.

22. Clark C, Downs RT. Using the American Mineralogist Crystal Structure Database in the Classroom. American Mineralogist. 2004;88:(1):247-50. 